Data Article

\title{
Application of unsymmetrical bis-chalcone compounds in dye sensitized solar cell
}

\author{
Tze Pei Phan ${ }^{\mathrm{a}}$, Kien Yung Teo ${ }^{\mathrm{a}}$, Zhi-Qiang Liu ${ }^{\mathrm{b}}$, Jenn-Kai Tsai ${ }^{\mathrm{c}}$, \\ Meng Guan Tay ${ }^{\mathrm{a}, *}$ \\ a Faculty of Resource Science and Technology, Universiti Malaysia Sarawak, Kota Samarahan, Sarawak 94300, Malaysia \\ ${ }^{\mathrm{b}}$ State Key Lab of Crystal Materials, Shandong University, Jinan 250100, China \\ ${ }^{\mathrm{c}}$ Department of Electronic Engineering, National Formosa University, Yunlin County 63201, Taiwan
}

\section{A R T I C L E I N F O}

\section{Article history:}

Received 15 May 2019

Revised 8 July 2019

Accepted 9 July 2019

Available online 11 July 2019

\section{Keywords:}

Push pull effect

$\pi$-conjugated system

Unsymmetrical bis-chalcone

Dye sensitized solar cell (DSSC)

Conversion efficiency

Crystal structure

\begin{abstract}
A B S T R A C T
A total of nine unsymmetrical bis-chalcone compounds have been synthesized and spectroscopically characterized. The unsymmetrical bis-chaclone compounds were substituted with either methoxy $(\mathrm{OMe})$ or chloro $(\mathrm{Cl})$ as the electron donor, and either difluoroboryl $\left(\mathrm{BF}_{2}\right)$ or a ruthenium(II)-dimethylsulfoxide [ $\mathrm{Ru}(\mathrm{II})$-DMSO] complex as the electron acceptor. All these compounds were used as the dye sensitizer in dye sensitized solar cell (DSSC) by using fluorine doped tin oxide (FTO) glass coated with titanium(IV) oxide $\left(\mathrm{TiO}_{2}\right)$ as the working electrode, and the indium tin oxide (ITO) glass coated with platinum as the counter electrode. The conversion efficiency of fabricated DSSCs were tested and the unsymmetrical bis-chalcone compound with $\mathrm{OMe}$ and $\mathrm{BF}_{2}$ substituents in the same molecule recorded the highest efficiency at $0.091 \%$. In contrast, the unsymmetrical bis-chalcone with OMe and $\mathrm{Ru}(\mathrm{II})$-DMSO complex has the lowest efficiency at $0.001 \%$.
\end{abstract}

(c) 2019 Elsevier B.V. All rights reserved.

Specifications Table [please fill in right-hand column of the table below].

\begin{tabular}{ll}
\hline Subject area & Organic and inorganic chemistry, and solar energy \\
Compounds & Unsymmetrical bis-chalcones \\
Data category & Spectroscopic spectral, elemental analysis, X-ray crystallography and solar cell conversion efficiency \\
Data acquisition format & NMR, IR, UV-vis spectra, X-ray crystallographic data, conversion efficiency and incident photon-to-current conversion \\
& efficiency \\
Analyzed and interpreted & Nine unsymmetrical bis-chalcone compounds have been synthesized and analyzed. The compounds were used as the dye \\
Data type & in DSSC and the conversion efficiencies were determined \\
Procedure & The data can be obtained from the present paper and supplementary information \\
Data accessibility &
\end{tabular}

\section{Rational}

The dye molecule in a dye sensitized solar cell (DSSC) plays an important role in absorbing energy from visible light, transferring excited electrons to the conduction band of $\mathrm{TiO}_{2}$ and also receiving electrons from the redox reaction in order to repeat the cycle $[1,2]$. In general, an ideal dye molecule possesses several properties which firstly, include excellent stability in the excited, ground and oxidized states. Secondly, strong absorption capacity in the visible range under radiance

\footnotetext{
* Corresponding author.

E-mail address: mgtay@unimas.my (M.G. Tay).
} 